\title{
Waiting-list induced proctitis: The hydrogen peroxide enema
}

\author{
S Ian Gan MD FRCPC, Lawrence M Price MD FRCPC
}

\begin{abstract}
SI Gan, LM Price. Waiting-list induced proctitis: The hydrogen peroxide enema. Can J Gastroenterol 2003;17(12):727-729.

Hydrogen peroxide is a widely available disinfectant that has been reported to cause colitis. We report a case of a 67-year-old man who presented with an acute proctitis caused by a self-inflicted $3 \%$ hydrogen peroxide enema. The patient's intention was to cure himself of a recently diagnosed prostate cancer, because the waiting list for oncological consultation was deemed too long. The pathogenesis of hydrogen peroxide mucosal injury and a review of the literature is discussed.
\end{abstract}

Key Words: Chemical; Colitis; Enema; Hydrogen peroxide; Proctitis

\section{Rectite causée par un lavement au peroxyde d'hydrogène et liée à une liste d'attente trop longue}

Le peroxyde d'hydrogène est un désinfectant facilement accessible, connu pour causer des colites. Voici le cas d'un homme de 67 ans qui est venu consulter pour une rectite aiguë, provoquée par l'auto-administration d'un lavement avec une solution de peroxyde d'hydrogène à $3 \%$. Son intention était de guérir un cancer de la prostate diagnostiqué depuis peu parce qu'il jugeait trop longue la liste d'attente pour une consultation en oncologie. Il sera question dans le présent article de la pathogenèse des lésions causées à la muqueuse par le peroxyde d'hydrogène et on fera un survol de la documentation sur le sujet.
$\mathrm{H}$ ydrogen peroxide has been used in a variety of clinical applications in gastroenterology. These include therapy for meconium ileus and fecal impaction, radiological localization of gastrointestinal hemorrhage and the demonstration of rectovaginal fistulae (1-5). While these techniques have been all but abandoned, more recently Wu et al (6) and Kalloo et al (7) both reported using 3\% hydrogen peroxide in visualization of acute upper gastrointestinal bleeding. Finally, hydrogen peroxide has also been used widely as an endoscopic disinfectant. This practice has led to several reports of inadvertent iatrogenic hydrogen peroxide-induced enteritis (8-10).

While self-induced chemical injury to the esophagus is not uncommon, acute proctitis and colitis are more rare incidents in the medical literature. We describe the case of a limited proctitis caused by a self-administered hydrogen peroxide enema.

\section{CASE PRESENTATION}

A 67-year-old man presented to the emergency room complaining of profuse diarrhea, tenesmus and urgency over a $24 \mathrm{~h}$ period. The diarrhea was initially nonbloody but had subsequently turned bright red in color. Past medical history included only type II diabetes mellitus with no known complications. He had no significant history of gastrointestinal disease. Medications included metformin and glyburide. There was no history of nonsteroidal anti-inflammatory drug use, and the use of metformin long preceded the diarrhea. The patient had no history of travel or antibiotic use. His only risk factor for ischemic colitis was his diabetes. Physical examination revealed a soft and nontender abdomen. Rectal examination was normal other than a diffusely hardened prostate. The patient was afebrile but had a white blood cell count of 15.7 $\left(\times 10^{9} / \mathrm{L}\right)$. His hemoglobin level was normal. Gastroenterology was consulted.

After closer questioning, the patient disclosed that he had recently been diagnosed with prostate cancer on rectal biopsy. While the biopsy had been performed two weeks before, he had only received the results two days before presentation. Subsequent to his diagnosis, he was then told that his appointment to be seen at the local cancer agency would be in seven to eight week's time. On returning home, the patient was so distraught with the waiting period that he attempted to cure himself by way of what he believed to be a caustic enema. Believing the prostate gland lay somewhere in the rectal vault, the patient reported using $100 \mathrm{~mL}$ to $200 \mathrm{~mL}$ of $3.5 \%$ hydrogen peroxide per rectum.

A flexible sigmoidoscopy showed a friable, inflamed mucosa within the rectum. Several white patches were visible in the areas of inflammation (Figures $1 \mathrm{~A}$ and $1 \mathrm{~B}$ ). The proctitis extended to approximately $15 \mathrm{~cm}$ and then tapered to normal.

The patient was discharged home. The diarrhea abated as did the blood per rectum. A repeat sigmoidoscopy 10 days later revealed the area to have healed almost completely. Only mild areas of erythema were still visible. Biopsies were taken and failed to reveal any signs of fibrosis or scarring. The patient was started on hormonal treatment for his prostate cancer in the interim.

\section{DISCUSSION}

Chemical colitis is not uncommon. Several reports of various substances causing colonic inflammation exist. These include soap, lye, ammonia, glutaraldehyde, potassium permanganate,

Division of Gastroenterology, Dept of Medicine, Foothills Medical Centre, University of Calgary, Calgary, Alberta

Correspondence: Dr S Ian Gan, G163, GI Clinic Area 2, University of Calgary Medical Clinics, 3350 Hospital Drive, Calgary, Alberta

T2N 4N1. Telephone 403-210-9359, fax 403-210-9368, e-mail driangan@hotmail.com

Received for publication April 3, 2003. Accepted June 9, 2003 


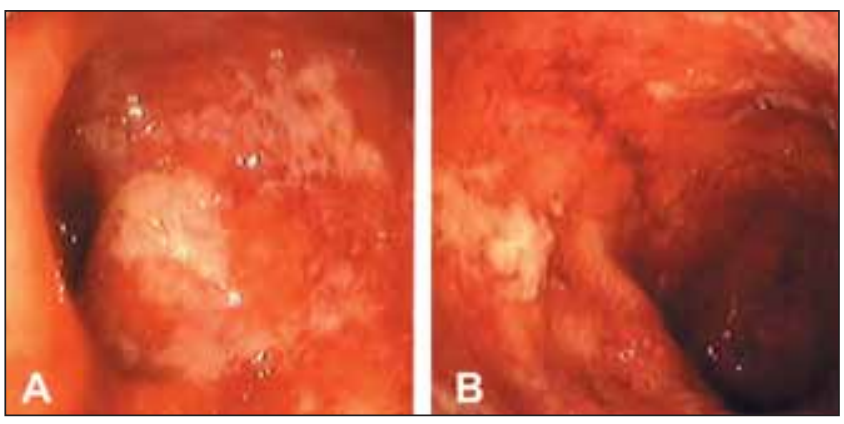

Figure 1) Hydrogen peroxide proctitis. A Endoscopic appearance of the distal rectum demonstrating the 'snow-white sign' and mucosal erythema and edema; $\mathbf{B}$ Linear erosions and white plaques in the proximal rectum

vinegar, chloroxylenol and chlorhexidine (11-14). While all these chemicals likely have a direct irritant and/or caustic effect on the mucosa, the mechanism of damage by hydrogen peroxide to colonic mucosa is unique.

The pathogenesis of hydrogen peroxide colitis has been reported to be secondary to penetration of the chemical into the mucosa with subsequent production of oxygen $\left(2 \mathrm{H}_{2} \mathrm{O}_{2} \rightarrow 2 \mathrm{H}_{2} \mathrm{O}+\mathrm{O}_{2}\right)$. Experimental models have shown that after seconds of exposure, the colon becomes distended, white and bloodless. Microscopically, minute gas cysts form as a result of oxygen production in both mucosa and submucosa within $1 \mathrm{~min}$ of exposure, followed by vascular congestion, focal hemorrhage and ulceration (15). Gas bubbles infiltrate the large veins and lymphatics and can be noted in the portal vein, right side of the heart, liver, lungs and inferior vena cava. Fatal gas embolisms have also been reported (15-17). Due to the rapid decomposition of the hydrogen peroxide by tissue catalase, the majority of damage is transient. When followed over time, however, the mucosa can progress to become gangrenous and necrotic.

Reports of hydrogen peroxide colitis are sparse in the literature. In 1951, Pumphery (18) reported two patients with acute colitis following hydrogen peroxide enema. Sheehan (19) delineated the pathogenesis of the disease by animal experimentation, after describing another case of hydrogen peroxide colitis (19). By 1981, when Meyer et al (20) reported three more patients with hydrogen peroxide colitis, the use of hydrogen peroxide enema for various therapeutic and diagnostic procedures was already uncommon.

Renewed interest in this phenomenon occurred in the past two decades, after four reports of a total of 22 cases of inadvertent iatrogenic hydrogen peroxide exposure to the colon. All of these 22 cases were attributed to contamination of the airwater channels of the colonoscope $(8-10,21)$. Most episodes occurred in relation with a 'final rinse' of the channels using $3 \%$ hydrogen peroxide solution before or after glutaraldehyde submersion. Bilotta and Waye (8) reported on seven of these patients, and coined the "snow white" sign caused by mucosal whitening after peroxide exposure. Jonas et al (10) noted that these endoscopic findings of discrete and confluent plaques could be mistaken for pseudomembranous colitis. The authors recommended that hydrogen peroxide be avoided in the final phase of cleansing. Interestingly, glutaraldehyde, the other agent commonly used in colonoscope disinfection, has also been reported as causing a unique form of acute iatrogenic colitis
(22). The cases occurred shortly after the introduction of a $2.0 \%$ glutaraldehyde solution (in contrast to a previously used $0.2 \%$ solution) and were generally associated with inadequate rinsing of the channels. A second source of glutaraldehyde proved to be from within the tubing used to connect the water bottles to the endoscopes. Similar to the hydrogen peroxide cases, patients presented with tenesmus, bright red blood per rectum and abdominal cramping. Pathology was indistinguishable from ischemic colitis. Another relatively recent report (23) of glutaraldehyde colitis involved six cases that were attributed to an automatic scope-disinfecting machine. The authors stated that the problems could be avoided by repeatedly changing rinse water, force-air drying the channels and washing endoscopes before use (23). This was confirmed in a study in 2001 that found that after machine disinfection, there was no significant glutaraldehyde residue in the scope if the scope was soaked for $5 \mathrm{~h}$ in saline and if the channels were rinsed (24).

A more unfortunate aspect to this case is the anxiety state that led to the self-induced proctitis. Waiting lists for almost all procedures and consultations continue to grow in Canada, but a particular need has been identified in oncology (25-27). These waits are difficult to avoid under the current economic and resource limitations and, therefore, special attention should to be paid to the emotional burden that a new diagnosis of cancer may impose. Certainly in our patient, his belief was that his condition was imminently fatal and that two months was far too long to go with hormonal treatment alone. With appropriate follow-up and proper counseling as to the nature, course, prognosis and treatment of the specific disease, it may be possible to avert such potentially disastrous situations.

\section{REFERENCES}

1. Henry G. Detection of gastrointestinal bleeding with barium hydrogen peroxide mixture. Am J Radiol 1957;78:569-72.

2. Cheong DM, Nogueras JJ, Wexner SD, Jagelman DG. Anal endosonography for recurrent anal fistulas: Image enhancement with hydrogen peroxide. Dis Colon Rectum 1993;36:1158-60.

3. Olim CB, Ciuti A. Meconium ileus: A new method of relieving obstruction. Ann Surg 1954;140:736-9.

4. Govoni A, Braitsford JF, Mucklow EH. The use of hydrogen peroxide for the elimination of gas from the intestine during roentgenography of the abdominal viscera. Am J Radiol 1954;71:235-8.

5. Poen AC, Felt-Bersma RJ, Eijsbouts QA, Cuesta MA, Meuwissen SG. Hydrogen peroxide-enhanced transanal ultrasound in the assessment of fistula-in-ano. Dis Colon Rectum 1998;41:1147-52.

6. Wu DC, Lu CY, Lu CH, et al. Endoscopic hydrogen peroxide spray may facilitate localization of the bleeding site in acute upper gastrointestinal bleeding. Endoscopy 1999;31:237-41.

7. Kalloo AN, Canto MI, Wadwa KS, et al. Clinical usefulness of $3 \%$ hydrogen peroxide in acute upper GI bleeding: A pilot study. Gastrointest Endosc 1999;49:518-21.

8. Bilotta JJ, Waye JD. Hydrogen peroxide enteritis: The "snow white" sign. Gastrointest Endosc 1989;35:428-30.

9. Schwartz E, Dabezies MA, Krevsky B. Hydrogen peroxide injury to the colon. Dig Dis Sci 1995;40:1290-1.

10. Jonas G, Mahoney A, Murray J, Gertler S. Chemical colitis due to endoscope cleaning solutions: A mimic of pseudomembranous colitis. Gastroenterology 1988;95:1403-8.

11. da Fonseca J, Brito MJ, Freitas J, Leal C. Acute colitis caused by caustic products. Am J Gastroenterol 1998;93:2601-2.

12. Pike BF, Phillippi PJ, Lawson EH Jr. Soap colitis. N Eng J Med 1971;285:217-8.

13. Orchard JL, Lawson R. Severe colitis induced by soap enemas. South Med J 1986;79:1459-60.

14. Hardin RD, Tedesco FJ. Colitis after Hibiclens enema. J Clin Gastroenterol 1986;8:572-5. 
15. Shaw A Cooperman A, Fusco J. Gas embolism produced by hydrogen peroxide. N Engl J Med 1967;277:238-41.

16. Mullins ME, Beltran JT. Acute cerebral gas embolism from hydrogen peroxide ingestion successfully treated with hyperbaric oxygen. J Toxicol Clin Toxicol 1998;36:253-6.

17. Christensen DW, Faught WE, Black RE, Woodward GA,

Timmons OD. Fatal oxygen embolization after hydrogen peroxide ingestion. Crit Care Med 1992;20:543-4.

18. Pumphery R. Hydrogen peroxide proctitis. Am J Surg 1951;81:60.

19. Sheehan JF, Brunjolfsson G. Ulcerative colitis following hydrogen peroxide enema. Lab Invest 1960;9:151-68.

20. Meyer CT, Brand M, DeLuca VA, Spiro HM. Hydrogen peroxide colitis: A report of three patients. J Clin Gastroenterol 1981;3:31-5.

21. Ryan CK, Potter GD. Disinfectant colitis. Rinse as well as you wash. J Clin Gastroenterol 1995;21:6-9.

22. West AB, Kuan SF, Bennick M, Lagarde S. Glutaraldehyde colitis following endoscopy: Clinical and pathological features and investigation of an outbreak. Gastroenterology 1995;108:1250-5.
23. Rozen P, Somjen GJ, Baratz M, Kimel R, Arber N, Gilat T. Endoscope-induced colitis: Description, probable cause by glutaraldehyde, and prevention. Gastrointest Endosc 1994:40:547-53.

24. Dietze B, Neumann H, Mansmann U, Martiny H. Determination of glutaraldehyde residues on flexible endoscopes after chemothermal treatment in an endoscope washer-disinfector. Endoscopy 2001;33:529-32.

25. Cormack DV, Fisher PM, Till JE. A study of waiting times and waiting lists for radiation therapy patients. Can J Oncol 1996;6:427-34.

26. Mackillop WJ, Fu H, Quirt CF, Dixon P, Brundage M, Zhou Y. Waiting for radiotherapy in Ontario. Int J Radiat Oncol Biol Phys 1994;30:221-8.

27. Mackillop WJ, Zhou Y, Quirt CF. A comparison of delays in the treatment of cancer with radiation in Canada and the United States. Int J Radiat Oncol Biol Phys 1995;32:531-9. 


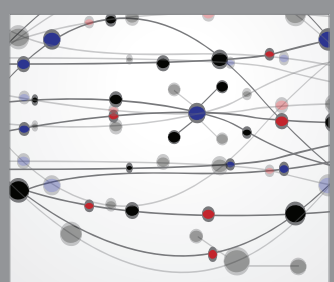

The Scientific World Journal
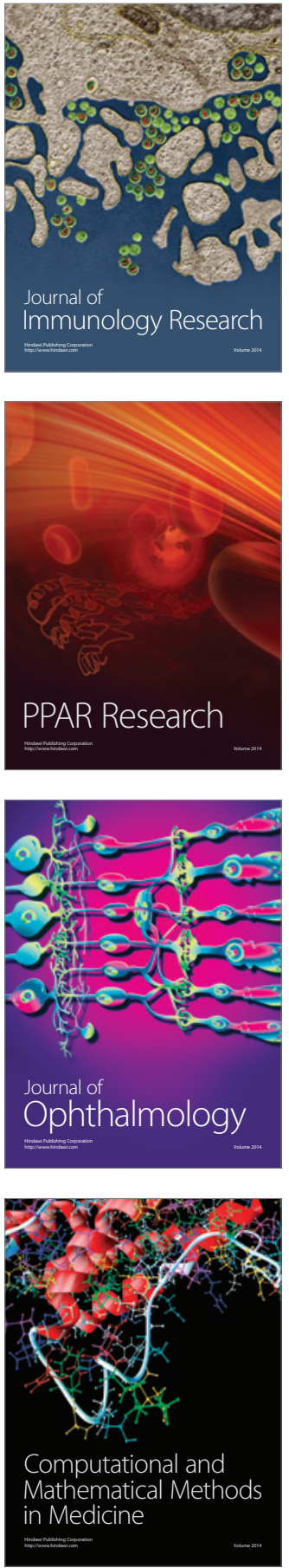

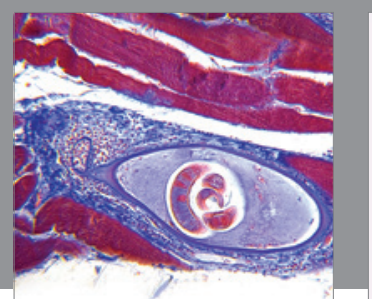

Gastroenterology Research and Practice

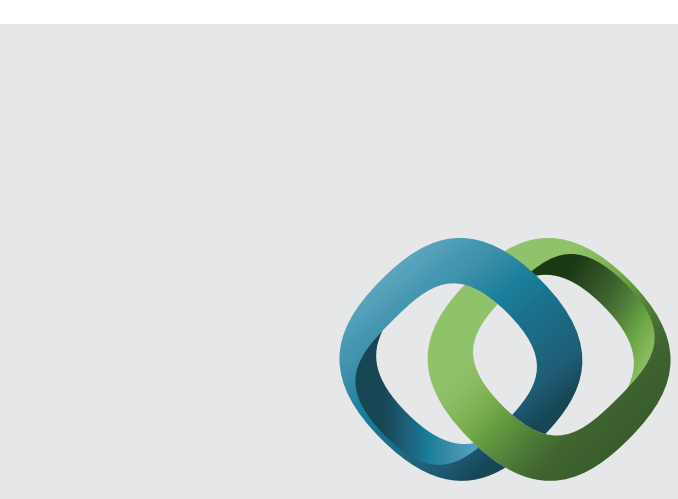

\section{Hindawi}

Submit your manuscripts at

http://www.hindawi.com
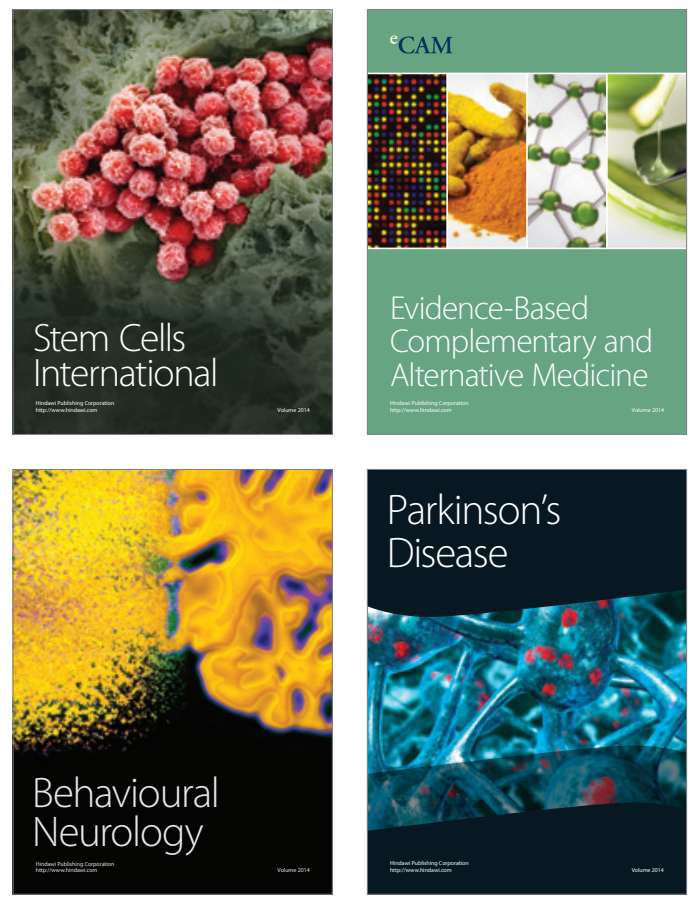
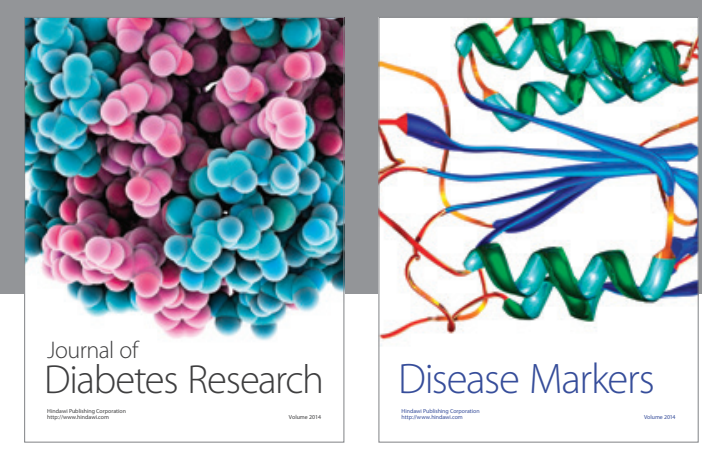

Disease Markers
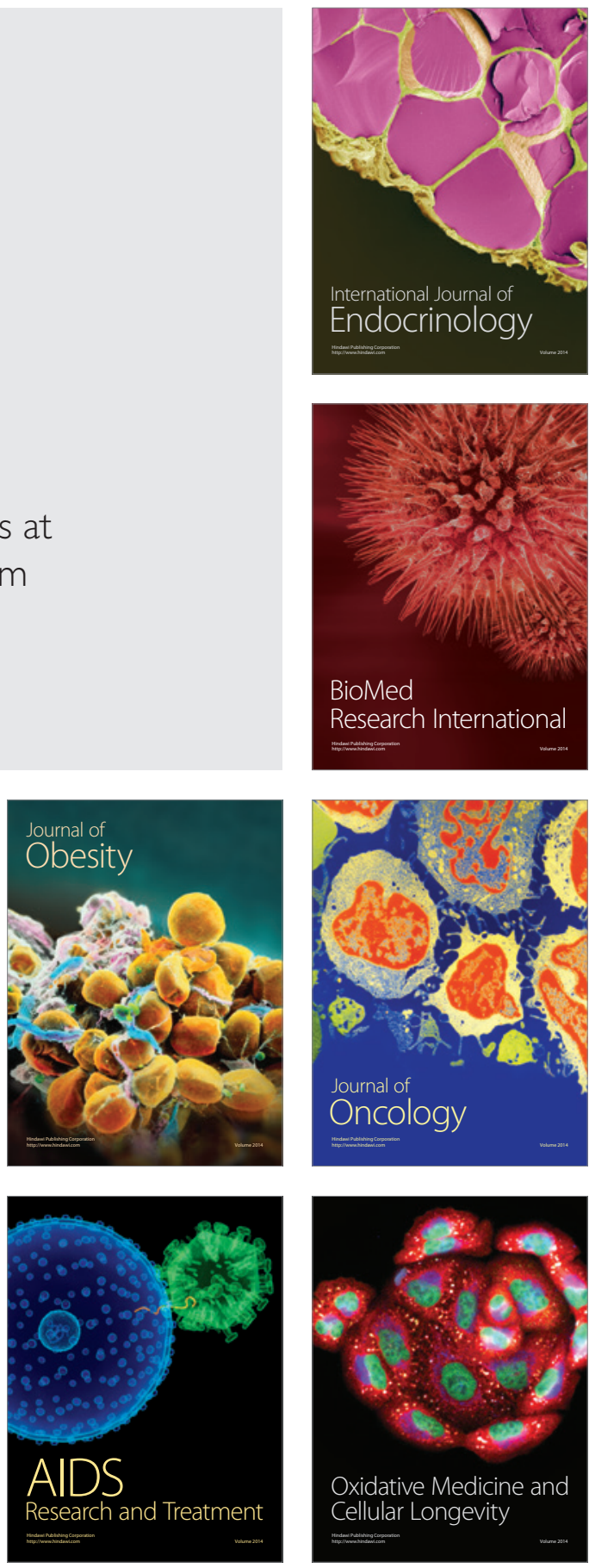